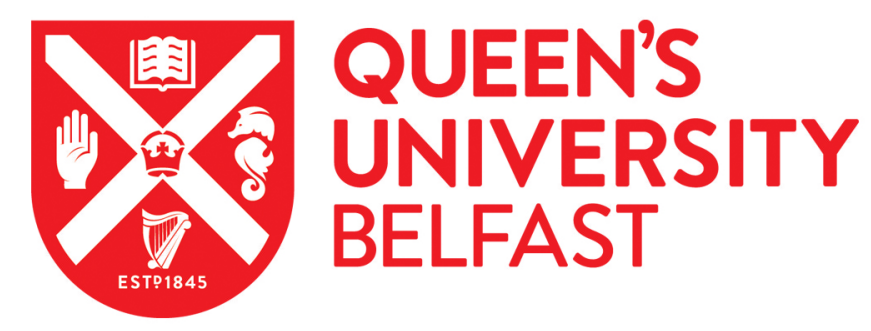

\title{
Linking Family Engagement with a Rights Perspective: Macro Factors Influencing Practice
}

Duffy, J., Collins, M., \& Hyun Kim, S. (2016). Linking Family Engagement with a Rights Perspective: Macro Factors Influencing Practice. European Journal of Social Work, 21(1), 45.

https://doi.org/10.1080/13691457.2016.1255925

\section{Published in:}

European Journal of Social Work

Document Version:

Peer reviewed version

Queen's University Belfast - Research Portal:

Link to publication record in Queen's University Belfast Research Portal

Publisher rights

This is an Accepted Manuscript of an article published by Taylor \& Francis in European Journal of Social Work on 30/11/2016, available online: http://www.tandfonline.com/10.1080/13691457.2016.1255925

\section{General rights}

Copyright for the publications made accessible via the Queen's University Belfast Research Portal is retained by the author(s) and / or other copyright owners and it is a condition of accessing these publications that users recognise and abide by the legal requirements associated with these rights.

Take down policy

The Research Portal is Queen's institutional repository that provides access to Queen's research output. Every effort has been made to ensure that content in the Research Portal does not infringe any person's rights, or applicable UK laws. If you discover content in the Research Portal that you believe breaches copyright or violates any law, please contact openaccess@qub.ac.uk. 
Linking Family Engagement with a Rights Perspective:

Macro Factors Influencing Practice 


\title{
Linking Family Engagement with a Rights Perspective: Macro Factors Influencing Practice
}

\begin{abstract}
While child welfare practitioners in many countries are struggling to develop methods of effective family engagement, they operate within different national and cultural contexts which influence, both positively and negatively, the ability to engage with families. Increasingly, international comparisons are necessary to further understanding of the development of social work practice. This is particularly necessary because most countries utilize international frameworks (such as the United National Convention on the Rights of the Child) to provide guidance in the development of policies, programs, and interventions. Each country (and locality) struggles to advance practice to be more effective and humane. Our paper offers a comparative analysis focused on familyoriented and rights-based frameworks of different countries. Based on a review of current national policies and a review of the literature regarding family based practices, we examine similarities and differences among four countries: the United Kingdom, Sweden, the United States, and South Korea. These countries were selected because they have some similarities (advanced industrialized democracies, professional social work, formal child protection systems) but have some differences in their social welfare systems (policies, specific practices, socio-cultural context). These differences can be
\end{abstract}


utilized to advance understanding regarding the promise and potential for family engagement strategies. We then discuss the utility of this comparison for theorybuilding in the arena of child care practice and conclude by identifying the challenges and limitations of this work.

Key words: Child care policy and practice, Family group conferencing, Children's rights, Comparative child welfare 


\section{Introduction}

It is difficult to conceive that child welfare practice has often understated the importance of meaningfully engaging with families and children (Smith et al. 2012; Buckley et al. 2011; Damman: 2014: Munro, 2011). At the same time, we know from research that good outcomes attach to social work practice which is positive, partnership and strengths based (Jowitt and O'Loughlin, 2005: Trotter, 2006; Smith, 2008; Saleeby, 2009; Trevithick, 2012). Thus, an enhanced attention to the importance of families and efforts to engage families in partnership are welcome developments.

This is an area of practice that resonates across the globe; consequently, international comparisons are appropriate (Gilbert et al. 2011). While practitioners in many countries are struggling to develop methods for effective family engagement, they operate within different national and cultural contexts (Authors, 2012). Our paper, therefore, offers a critical stance by outlining the types of macro challenges and opportunities, inherent to the social work practice landscape, which can meaningfully facilitate or negate the types of progressive practice which 'family engagement' is calling for. Our research question is: How does family engagement practice in child welfare vary in differing national contexts? To address this question, we examine different legislative frameworks, with particular emphasis on rights and different aspects of cultural context. 


\section{Background}

Family engagement. Extensive literature has been devoted to the importance of practice that is family centered, including an articulation of the philosophy and the belief that shifting toward a family-centered approach will result in a better system and improved outcomes (Spratt and Callan, 2004; Cree and Davis, 2007; Smith et al. 2011; Buckley et al. 2011). Recognizing the centrality of families, numerous program models related to "family" are part of the practice landscape (McCroskey \& Meezan, 1998). This is an indication of the agreed upon importance of work with families. Phrases such as "family support" (Kagan \& Weissbourd, 1994), "family participation" (Morris, Brandon, \& Tudor, 2015), "family partnership" (Roose, Roets, Van Houte, Vandenhole \& Reynaert, 2013), "family group decision making" (Buford, 2000) and similar concepts have been used to reflect variations of this work. In some cases family-centered approaches focus on core principles working with families (e.g., Krumer-Nevo, 2003) and in other cases they refer to specific program models (e.g., Gerring, Kemp, \& Marcenko, 2008).

Receiving significant current attention is the specific model of family group conferencing which has captured the attention of many child welfare systems in the US, the UK, Australia, and elsewhere. These conferences involve key members of the family's environment to discuss and determine a plan of action for the family and child. Examples of recent research reports have included descriptions of the intervention and issues in implementation (Darlington, et al., 2010), its utilization in specific settings (Rauktis, et al., 2010), and challenges to adapting the model to various cultural groups (Waites, et al., 2004). 
We utilize the concept of "family engagement" as the term guiding our analysis. This term does not denote a specific program model (such as family group decision-making) nor is it as broad as "family support" which may include a variety of welfare-oriented interventions not specific to child welfare systems. Our focus on "family engagement" is related to our orientation to rights-based frameworks in our analysis; i.e., families must first be engaged in order to effectively use their rights to participate (Bell, 2002; Spratt and Callan, 2004). Moreover "engagement" puts the onus of the intervention on the worker's efforts to ensure families are able to participate in the activities of the child welfare system.

Rights-frameworks. There is extensive world-wide debate on issues of child and family rights (Lundy, 2007; Munro, 2011; Winter, 2011; 2014). For our purposes, we are primarily focused on a key nexus of children and family rights: children have a right to be raised by their family, and, consequently, families have a right to appropriate support in order to raise their children. In regard to family engagement in child welfare practice specifically, participatory decision-making is critical, requiring child and family voice in decisions supported by professionals and statutory authorities.

The United Nations Convention on the Rights of the Child (UNCRC, 1989) is the foremost children's rights framework utilized across the globe (Cohen, 1992; Freeman and Veerman, 1992: Detrick, 1999; Author, 2010; Manful and McCrystal, 2010; Young et al, 2014). The UNCRC sets out the rights that are needed if children are to develop to their full potential. By ratifying the Convention, governments are stating an intention 
to put a rights-based commitment into practice. Particularly relevant to issues of family engagement are Articles 5 and 9 of the UNCRC asstated below:

Article 5: States Parties shall respect the responsibilities, rights and duties of parents or, where applicable, the members of the extended family or community as provided for by local custom, legal guardians or other persons legally responsible for the child, to provide, in a manner consistent with the evolving capacities of the child, appropriate direction and guidance in the exercise by the child of the rights recognized in the present Convention.

Article 9: States Parties shall ensure that a child shall not be separated from his or her parents against their will, except when competent authorities subject to judicial review determine, in accordance with applicable law and procedures, that such separation is necessary for the best interests of the child. Such determination may be necessary in a particular case such as one involving abuse or neglect of the child by the parents, or one where the parents are living separately and a decision must be made as to the child's place of residence. 2 . In any proceedings pursuant to paragraph 1 of the present article, all interested parties shall $\underline{\text { be given an opportunity to participate in the proceedings and make their }}$ views known (our emphasis)

All countries of the world, except the United States, are signatories to the UNCRC. Yet, despite its widespread adoption, this document does not easily translate into practice 
(Young et al, 2014). Consistent with an international comparative approach, the actual implementation of practices that ensure these rights, can be variable across countries and dependent on political will for translation to practice (Bainham, 2005; Manful and McCrystal, 2010).

International comparison. In our increasingly globalized world there is widespread interest in conducting international comparisons of policy and practice. Having some level of understanding of varying systems, and one's own system in comparison to others, is fast becoming requisite in order to competently address the needs of children and families. Recent book-length comparative treatments have focused on child protection systems (Gilbert, et al., 2011) and foster care (Colton \& William, 2006). International comparisons in journal articles are necessarily more limited in scope (e.g., Desai, 2009; Mildred \& Plummer, 2009). An underlying goal of much of this research is to develop understanding of how potential solutions are developed in some nations and the critical factors that influence the development of various approaches. Methodological limitations on the number of countries for comparison and the numerous potential explanatory variables are particularly well suited for case study comparative methods rather than quantitative analyses (Collier, 1993).

Analyses typically aim to develop frameworks which categorize countries on some dimensions and identify key variables potentially explaining these dimensions. For example, Gilbert (1997) categorized child abuse reporting systems as either child protection or family services and distinguished four key dimensions. The recent work by 
Gilbert, et al. (2011) provides a more extensive and up-to-date treatment of national comparisons of systems of child protection, in particular identifying the role of social welfare systems (e.g., expenditures on family benefits). Additionally they note that recent developments in social welfare policies among OECD counties have indicated a tendency to "recognize children as independent beings and not only as future adults or as the property of their parents, which raises the issue of how best to achieve an appropriate balance between children's rights and parents' rights" (p.11).

Despite the apparent importance of socio-cultural, as well as economic factors in shaping child welfare policies and practices, far fewer studies have included poor or non-Western countries in their international comparisons. Part of this reason is the often lack of formal systems of protection; rather than a system focused on child protection specifically, with governmental authorities possibly having broader oversight of children's issues with particular focus on health and education (Collins, et al., 2009). This wide variation in the elements of the "system" can therefore make useful comparisons difficult.

While international variations are expected and appropriate, "family" as a concept is central to the human condition and has a high level of normative importance in virtually every culture (Daly, 2011). Because of its fundamental importance across cultures and because of the increasing prominence of family-focused strategies in the West, it is the core focus of our inquiry. 


\section{Methodology}

Beginning with a literature search, we suspected, and quickly confirmed, that the bulk of existing research evidence regarding family engagement would be concentrated within western industrialized countries, mostly the US, the UK, Australia and New Zealand with some attention in other European countries and Canada. We searched several databases (PsychINFO, Social Sciences Full-Text, Social Services Abstracts, Psychology + Behavioral Sciences Collection, ScienceDirect, JSTOR, PAIS International, Social Sciences Citation Index, Humanities and Social Science Retrospective) utilizing the search term "Family Engagement" with "Africa", "Asia", "Latin America/South America", and "Eastern Europe." Unfortunately this and other related searches identified numerous articles, the vast majority of which had nothing to do with the specific topic of family engagement in child welfare practice.

We therefore decided to purposively select four countries for our comparison. Two of these countries we were familiar with (the United Statesand United Kingdom). We also selected Sweden to provide a further European comparison given its reputation as "an advanced human welfare society" (Cocozza and Hort, 2011 in Gilbert et al. 2011:89 ). In an effort to move beyond Western (primarily English-speaking) countries, we also purposively selected South Korea for inclusion. This country has an industrialized economy and system of professional social work but also has cultural and other differences relevant to our comparison (Hong et al, 2011). One of the authors also has language capability to access necessary policy information for our review. 
The methodology applied in undertaking the various elements of this comparison draws from the works of Payne (2006) and Pinkerton (2008) and was applied in Authors' (2012) previously published work. Adopting Payne's 'partialising and comparative strategy' (2006:179), therefore facilitated the examination of key features of engagement in the different national contexts, whereby both comparisons and differences in practices could be highlighted. Furthermore, Pinkerton's emphasis on the need to factor in 'sources of national information' $(2008,247)$ suited the necessary part of this examination focused on the impact of macro factors. Thus, we were purposeful in selecting core features to include: 1 ) legislative frameworks related to (a) child welfare policy and (b) child/family rights; 2) status of family engagement as practice principle; 3) implementation, especially regarding the role of professional social work, and 4) cultural context.

Source information related to legislation frameworks (1a and $1 \mathrm{~b}$ ) was easily identified. Each of the four countries had specific national-level legislation relating to the child protection/child welfare system of the country. Although a full historical analysis was not possible, some specific developments were identified as related to more familyfocused legislation. Similarly, information related to family engagement as a practice principle was determined through a review of the published literature (as identified in the literature search identified above). Extracting information from the literature related to implementation and cultural context is less direct. This requires a broader knowledge of social work in each country and the underlying context. The authors represent three of the four countries reviewed and have tacit knowledge of social work practice and 
cultural context in these countries. As scholars, they also have an understanding of the scholarly literature on child welfare practice and can identify relevant broad themes.

Our analysis begins with a description of each country on the characteristics identified. Data were organized into a chart to highlight key elements. Moving beyond description, our analytic strategy then used an inductive approach to identify consistencies and differences in policy approaches. These observations led, in turn, to operating assumptions regarding the status of family engagement as a practice principle. These operating assumptions are the basis of theory building. Our discussion also identifies the limitations of this comparative approach.

\section{Findings}

United Kingdom (UK)

Of the four countries examined, attention to family engagement was most visible in the UK. Engagement with children is now an engrained legal and policy requirement, with numerous guidance documents on hand to assist practitioners in this area (Woolfson et al, 2010). The implementation of the Human Rights Act (1998), adopting the European Convention on Human Rights (ECHR) as well as the ratification of the UNCRC have been significant in placing a rights agenda at the forefront of micro level family and child care practice (Author, 2010; 2012). Consequently, social workers are legally mandated to adhere to fundamental human rights requirements in their practice. Article 6 of the ECHR stipulates the Right to a Fair Trial which in social work nomenclature is interpreted as the right to participate/to be heard when at stake is a legal consideration 
in relation to the child's/family's rights. The UNCRC similarly, through Article 12 , requires public authorities to involve children in decision making about important matters affecting their lives and is regarded as a lever for discussion and focus on how rights can be best realized (Roose \& De Bie, 2008). In addition, notions of serviceuser involvement (Author, 2008; Authors, 2012) and citizenship based social work (Author, 2005) are now firmly engrained in the broader landscape of health and social care in the UK.

Kirton (2009), also observes that concepts of prevention, children's rights and partnership all firmly took hold with the introduction of the Children Act in England and Wales (1989). Parton (2009) endorses the importance of the latter in stating: "The central principles of the Act encouraged an approach based on negotiation with families and involving parents and children in agreed plans in a spirit of 'partnership"' ( $p, 70)$. Despite these important legal requirements, the UK system of child welfare has oscillated between family support and child protection in its emphasis (Spratt and Callan, 2004; Hayes and Spratt, 2009). Linked to this latter point, increasing evidence suggests that placing too much emphasis on child protection investigations, instead of preventative and partnership based services for children in need, does not necessarily result in better outcomes for children (Davey \& Bigmore, 2009). The Refocusing Debate was how this issue became expressed in professional parlance and underscored a plea to re-prioritise family support and partnership working, so central to the Children Act (1989). The publication of the Laming Report, following the death of Victoria Climbié, an eight year old child known to social services, was seminal in elevating child protection 
practice but particularly called on social workers to work in partnership with children to include their views as an inherent and necessary part of their protection (Laming, 2003). The subsequent publication of the aptly named Every Child Matters report (DfES, 2004), then further reinforced a commitment to safeguarding and promoting the welfare of children, placing children's interests centre-stage and emphasizing the need for all parties to work together (Jowitt \& O'Loughlin, 2005). Implicit within this call was the need for social workers to recognise the value of engagement in the discharge of their child protection functions. Similar calls for focusing on more engagement based approaches with children and parents were made in the aftermath of the death of Peter Connelly (referred to in the media as 'Baby P') in 2008. Winter (2011) aptly makes the point 'all children regardless of their age, can express a view' and it is social workers' responsibility to seek these views $(p, 402)$ in her reference to the absence of child focused practice in this tragic case. In the waves of analysis following this case, Munro also made a similar call: 'everyone involved in child protection should pursue childcentred working and recognise children and young people as individuals with rights, including their right to participation in decisions about them in line with their age and maturity' (2011, p.23). Munro also was critical of the absence of time that social workers were able to give to frontline social work due to the other heavy bureaucratic demands of their work. Kirton (2009) earlier pointed to problems of implementation in terms of achieving the twin objectives of child and parental engagement. Spratt and Callan (2004), however, concluded that meaningful engagement with parents was achievable through skilful social work intervention, a point also echoed in more recent research (see, for example, Smith et al ,(2012): Buckley et al. (2011; Damman, 2014). The Think 
Family policy initiative, introduced in 2008 , was also significant in re-prioritising the important role of the family in supporting children. Fundamental to this policy was the belief that in order to ensure better outcomes and life chances for children, adult services and children's services needed to be better coordinated and 'joined up'. The document itself makes this explicit: "excellent children's services and excellent adults' services are not enough in isolation. To transform life chances, and break the cycle of disadvantage, services must go further. They must 'think family' (Cabinet Office, Social Exclusion Task Force 2008, p. 4 quoted in Parton, 2009).

Child and family engagement in child protection in the UK therefore operates within a macro context which is quite heavily mandated by national and international legislation and a plethora of policy guidance. Nevertheless, even within such a prescribed context, UK social work practice with children and families is quintessentially child protection in orientation (Gilbert, 1997). Kirton (2009) suggests this is not a peculiarity to the UK and cites from the work of Katz and Hetherington (2006) in support of this point: "in contrast with much of continental Europe....'Anglo-Saxon' countries have tended to separate child protection from family support and give it primacy within the child welfare system" (p. 71).

\section{Sweden}

The situation in Sweden has a texture similar to that of the UK, yet equally, challenges around implementation arise. The Swedish child welfare system is described internationally as family orientated (Höjer \& Forkby, 2011) and strongly associated with family support in comparison to the UK's more child protection focus (Sundell et al, 
2001). Prior to getting to this progressive point however, Sweden had come from a background of negative publicity surrounding excessive intervention into family life and removal of children into care (Olsson Hort, 1997).

A range of progressive legislation culminating in the 1980 Social Service Act, however, saw Sweden embracing a commitment to social citizenship (Olsson Hort, 1997). This embodied the protection of rights, particularly for parents to maintain contact with their children, but more fundamentally to maintain them at home where possible. The concepts underpinning this commitment to citizenship would involve the state in maintaining kinship defence and family ties, promoting voluntary measures in terms of intervention and promoting parents' rights, but still maintaining the importance of child protection through the Care of Young Persons Act (1990).

Partnership working in Sweden with children and parents is therefore an embedded feature in the social work response to child protection. In any situation where alternative care has to be considered, a constant feature of this requires always considering family re-unification. The setting of timetables for reviewing such cases is written into the primary legislation, the Social Service Act, stipulating that reviews must be held a minimum of once every six months. Similar to the Children Act in the UK, mentioned earlier, where voluntary arrangements cannot be achieved with parents, the state has recourse to intervention; however family reunification and parents' rights to appeal are key principles in terms of moderating the relationship between the state and the private domain of family life.

Sweden's model of child welfare therefore comprises four important elements: "a greater readiness to intervene, child welfare is assessment driven, best interests are 
broadly defined to include well-being within family preservation, more resources are available to support families and prevent harm" (Khoo et al, 2002, 465). In practice this results in less proceduralized ways of working. While legislation provides the framework of the child protection system and provides guidelines; municipalities and the workers at the municipal level design the practice features of child protection (Cocozza \& Hort, 2011). Furthermore, Norström and Thunved (1996 in Khoo et al, 2002), endorse the view that preservation of the family is a very significant ideological driver contextualising state intervention. It is also noted that such responses occur within an overarching rights based framework which articulates children's best interests: "a general welfare consensus there combined with a broad, rights-based framing law means that social workers have the professional latitude to ensure that the child has 'good enough' living conditions" (Khoo et al, 2002, 466).

A considerable amount of time must, however, be devoted to assessment as a consequence of investing time in partnership. A typical assessment with a child and family may take up to four months (Khoo et al, 2002). An added concern is the fact that in a child welfare driven model, some child protection cases may in fact go undetected as "... social workers in Sweden are not specifically trained to recognise, classify or process abuse cases differently...." (Khoo et al, 2002, 467). Furthermore, Cocozza and Hort (2011) note that the role of professionalism in the social welfare sector is not firmly established and describes a "rather weak semi-professional estate" (p.103). The Swedish system has also attracted criticism for "....placing an undue emphasis on the views of parents and of not paying sufficient heed to the wishes and needs of the child" (Cameron \& Freymond, 2006 cited in Höjer \& Forkby, 2011, 95). 


\section{South Korea}

In South Korea, the Child Welfare Act (1961) established a legal framework for a child welfare system and provided selective services for children in need, such as orphans from the Korean War. In 1981, the Child Welfare Act was amended with a view to promoting the welfare of all children. Having said that, it still remained a selective welfare system that spent 90 percent of its expenditures for children who were not protected by their parents (Lee, 2011). In addition, the Child Welfare Act, revised in 1981, prohibited abusive behavior against children under penalty of fine or imprisonment. However, the law did not enforce this and lacked provision for a mandatory child abuse reporting system (Doe, 2000).

In the late 1990s, several cases of severe child abuse and neglect were intensively reported in the media, thus child welfare experts and advocacy groups pushed the revision of the law to include a mandatory reporting system (Lee, 2007). As a result, the Child Welfare Act was revised in 2000 and provided a legal basis for government intervention in cases of suspected child abuse and neglect. The revised law included provisions for providing a clear definition of child abuse and neglect, establishing of a 24-hour hotline, and creating national child protection agencies (Lee, 2007; Ju \& Lee, 2010). These provisions were also prepared to comply with the UNCRC (1989) recommendations for children's rights to live and their protection (Lee, 2011; Ju \& Lee, 2010).

Professional social work and child welfare practice can, however, conflict with traditional cultural values. Traditionally, South Korea is a paternalistic and hierarchical society with 
a strong influence of Confucianism (Yang \& Shin, 2008; Ju \& Lee, 2010). Confucianism has been the dominant cultural philosophy affecting the relationship between children and their families in Korean society andhas unique characteristics compared to western philosophy. For example, the family's superiority is more important than individual members. Furthermore, emphasis on filial piety and saving face as well as strict obedience by children to adult family members are differences in the two philosophies. Confucianism emphasizes blood-relatedness in keeping a family's continuity (Lee, 2007; Yang \& Shin, 2008; Kim et al., 2005). In application to the development of social welfare policies, Shin and Shaw (2003) suggest there has been a deliberate governmental strategy not to develop a supporting social infrastructure of modern welfare state packaged social services asthese types of policies might undermine the neo-Confucian tradition of family care for dependents.

In addition, 'saving face' as a Confucian cultural value emphasizes keeping family matters within the family (Lee, 2007). Because of this cultural tradition, family members prefer to solve family problems by themselves instead of seeking help. Also, people tend to be reluctant to report child abuse cases because they believe they would be violating the other family's dignity (Lee, 2007). One national survey on people's perceptions of child abuse and neglect shows that Koreans in general do not necessarily consider corporal punishment to be an abusive behavior because they tend to measure corporal punishment against their traditional values for raising children in keeping with adults' standard and expectations (Yoon, 1996). Doe (2000) argues that the practice of intentional and unintentional child maltreatment has been frequently 
ignored and strongly supported by the traditional social and cultural norm, which has highly valued parents' rights to discipline their children.

Since South Korea ratified the UNCRC in November of 1991, it has tried to comply with the UNCRC's recommendations to protect children's rights through legislative measures, such as the amendment of the Child Welfare Law (Ju \& Yang, 2010). Despite the government's efforts to ensure children's rights, the procedures to hear children's opinions or guarantee children's participation remain at an unsatisfactory level (NHRC, 2006). Parents play a central role in the planning and decision-making of their children thinking that their point of view is in 'the best interest of the child' (Yang \& Shin, 2008). According to the periodic report on the implementation of the UNCRC (RCW, 2005), "traditional thought and stereotypes in South Korea remain unchanged to the effect that children must be subject to adults," and "a deeply-rooted sense of authority and seniority prevail over society, discouraging children from expressing their views and being involved in decision-making processes."

Specific programs of family engagement in practice were not identified in our review. As the US and UK have more recently embraced principles of family engagement, it is likely other nations will do so as well. Given the cultural values identified, an emphasis on family would seem particularly well-suited to the South Korean context. Although formally adopting the UNCRC, specific implementation of a children's rights perspective in South Korea seems less consonant with traditional values. 


\section{United States}

In contrast to the three countries examined thus far, the US is not a signatory to the UNCRC. The reasons why the U.S. has not ratified the UNCRC are complex and related to legal, socio/cultural, and political considerations in the U.S. (Scherrer, 2012). Scherrer (2012) recently discussed the UNCRC as a strategy for child welfare in the United States. In discussing the arguments against CRC ratification in the U.S., he notes that oppositions to the CRC can be categorized in three areas: legal, social/cultural/religious, and political and provides examples of these from Mason (2005), Carter (2006), Gunn (2006), and Weissbrot (2006). Mason (2005) identified some of the ambivalence in the U.S. over children's participatory rights; some have been granted but their interests as generally not seen as being different from their parents. Carter (2006) noted the U.S. Constitution's protections of states' rights as a key reason why the U.S. is reluctant to engage in formal treaties that might limit states'

power. Others (Gunn, 2006; Weissbrodt, 2006) have noted political factors; some segments of the population may deliberately frame the CRC thereby distorting its meaning (e.g., loss of parental control to discipline, abortion rights) so as to appeal to certain segments of the population.

A child's rights perspective is, therefore, not an undergirding concept for child welfare practice in the U.S. nor is there language regarding child and family rights that is written into government policy. In the US, one of the primary sources of discord between social work and human rights practice is the distinctive "rights culture" (Glendon, 1992). This involves recognition of the U.S. constitutional structure and resulting policy that does not recognize "positive" rights (social and economic rights). 
In the U.S., Titles IV-B and IV-E of the Social Security Act provide the authority for state child welfare agencies to provide child protection, foster care, and other child welfare services (Administration for Children and Families, 2016). The explicit emphasis of the Adoption and Safe Families Act (ASFA) (1997) prioritizes child safety, accelerates permanency and simplifies procedures to terminate parental rights. The more recent Fostering Connections to Success and Increasing Adoption Act (2008) emphasizes efforts to move children from foster care to permanency and increase well-being of children in foster care. Particular to the focus on family engagement, the legislation increases resources for kinship care providers and provides a small amount of funding for family-focused initiatives including family group decision making as a model. Thus, this recent legislation suggests a modest movement toward a participatory model of family engagement.

In an effort to promote enhanced accountability for state child welfare systems, the federal government began the Child and Family Services Review (CFSR) process in 2000. States are assessed regarding their conformity with Federal requirements in areas of child protection, foster care, adoption, family preservation and support, and independent living services (Mitchell, Thomas and Parker, 2014). The CFSR process includes a statewide self-assessment, an onsite evaluation and a Program Improvement Plan (PIP) developed by the state to address areas of needed improvement. Safety, Permanency, and Family and Child Well-Being are the three outcome areas on which states are assessed in the CFSR process. Safety is listed first: "Children are, first and foremost, protected from abuse and neglect." This reflects the continuing primary 
concern of child protection. But the CFSR outcomes are also attentive to the broader focus on family. Specifically, "The continuity of family relationship and connections is preserved for families" and "Families have enhanced capacity to provide for their children's needs" each[s1] are therefore more consonant with a family rights and family engagement perspective. Indeed, the CFSR framework aims to balance both key elements of child welfare services and reflect the inherent challenges of the work (Mitchell, Thomas and Parker, 2014).

The process and outcomes of the CFSRs have begun to receive research attention. Mischen (2008) conducted a qualitative analysis of States' PIPs finding that some were engaging in promising strategies such as Family Team Meetings. These were found to occur with regularity in one of the sample states (Oregon). Vermont was also identified as having a high level of parental involvement. In terms of future efforts, as identified in the PIPs, Family Team Meetings were identified in at least five States in the sample. As family engagement practice continues to stimulate extensive interest, it is likely additional States have already, or will in the future, continue to examine the role of specific efforts such as Family Team Meetings in moving their States forward in working with families. In the US, efforts to reform child welfare practice have also been conducted in response to class action lawsuits (Center for the Study of Social Policy, 2012). This is another avenue by which States or other jurisdictions engage in familyoriented reforms.

These two examples (the use of state PIPs and responses to class action lawsuits) provide two mechanisms by which attention to family engagement processes have been advanced in the US. The US systems of child welfare are organized at the State and 
County level. Thus, there are often highly variable approaches in different locations throughout the country. The benefit of this Federal system is the ability to potentially learn what works in different settings. The limitation, however, is that there is often not a centralized and clear articulation of the direction and focus of policy and practice.

\section{Discussion}

This paper has aimed to provide a cross-national comparison regarding the macro context of child welfare that relates to the potential utilization of family engagement strategies. Each of the countries examined has professional child welfare practice but the countries differ in the emphasis on rights-oriented frameworks related to practice, the legal context of rights, and cultural considerations related to families and rights. The Table below provides a summative overview of those comparing and contrasting factors emerging from our cross national comparisons. We also include the implementation challenges we have observed. 
Table 1. International Comparison - Summary of Key Issues

\begin{tabular}{|c|c|c|}
\hline Country & Family Engagement & Challenges \\
\hline Sweden & $\begin{array}{l}\text { Family engagement and family } \\
\text { support are primary foci. }\end{array}$ & $\begin{array}{l}\text { Weakness in professional role, long } \\
\text { and protracted assessments where } \\
\text { the focus on child protection can } \\
\text { become diluted because of overt } \\
\text { focus on parents. }\end{array}$ \\
\hline United Kingdom & $\begin{array}{l}\text { Strong policy and legal policy context } \\
\text { driving focus on participation but } \\
\text { primarily child protection orientation. }\end{array}$ & $\begin{array}{l}\text { Highly procedural, regulated nature } \\
\text { of UK social work can mitigate } \\
\text { against family engaged practice. UK } \\
\text { policy has also been significantly } \\
\text { impacted by child abuse tragedies. }\end{array}$ \\
\hline United States & $\begin{array}{l}\text { Modest progression towards family } \\
\text { engagement in practice without a } \\
\text { policy and legislative context } \\
\text { promoting children's rights. }\end{array}$ & $\begin{array}{l}\text { Resistance to adopting formal } \\
\text { mechanisms for promoting and } \\
\text { recognizing children's rights. }\end{array}$ \\
\hline South Korea & $\begin{array}{l}\text { Cultural, country context strongly } \\
\text { influenced by Confucian philosophy } \\
\text { which elevates the importance of the } \\
\text { family. }\end{array}$ & $\begin{array}{l}\text { Power and impact of cultural norms } \\
\text { stressing privacy and primacy of the } \\
\text { family, undermine the child } \\
\text { protection orientation of social work } \\
\text { intervention. }\end{array}$ \\
\hline
\end{tabular}

The European countries in our comparison operate within the UNCRC and the European Convention on Human Rights. These international instruments support 'engagement', yet there are still serious problems evidencing real partnership practice. In the US, where there is no such underpinning legal requirement regarding child and family rights, there is, nonetheless, ideological movement towards family engagement 
and supporting initiatives, albeit on a small scale. South Korea offers an interesting comparison. It has professional child welfare systems and stated commitment to UNCRC guidelines. Cultural ideas about family, children, and rights, however, may provide a greater influence on policy and practice implementation.

Implementation mechanisms and cultural context appear to be two key factors in understanding the link between policy and practice. Recent comparative research by Benbenishty et al (2015:65) on factors impacting on decision making in child protection also concur with the importance of appreciating the impact of what they refer to as 'country context'. Our comparison illuminates several mechanisms by which stated policy (legislation and its guidance documents) is linked to practice with families. Implementation theories identify factors that facilitate or block accomplishment of stated policy goals (Hill \& Hupe, 2002). Some implementation challenges are common crossnationally but others can be specific to political and cultural context. For example, the challenge of child welfare systems operating in the public spotlight and subject to media scrutiny was a common theme in these four countries (this was also noted by Gilbert, et al., 2011; Benbenishty et al, 2015 and Wolf et al, 2011). But the impact may be variable depending on other elements of the policy setting. The influence is particularly strong in the UK which has routinely responded with a series of high level inquiries that forced changes in practice (Gilbert et al, 2011). On the other hand, in the U.S. the federal structure of government and the state-level operation of child welfare systems lessen the impact of media scrutiny. As a result of high profile tragedies and resultant media 
attention, there may be changes in state policies, increased resources, or calls for additional training. But the impact on federal policy is rare.

The practice of social work and the organizational setting in which it operates to deliver child welfare services is likely another key implementation factor that varies across countries. While each of the four countries has a profession of social work (supported by education, licensing, and other characteristics of professionalization) the specific role and organization of professional practice differs. In the UK, professional social work is characterized by extensive proceduralisation of practice subject to highly detailed guidance. Ferguson (2005:791) coined the term 'conveyor belt social work' as a metaphor for portraying the impact of proceduralism on practice. Although public systems of child welfare are the major service delivery system in the US, the historic and institutionalized role of the non-profit sector is also important. The profession of social work, and its role in child protection, does not have as long a history in either Sweden or South Korea. This may be both an impediment and a facilitator of implementation as discussed further below.

In this way, systems of training and other strategies of workforce development, may be a critical factor in policy implementation processes (Author, 2007) and may be of particular potential importance in the movement toward family engagement. Recognising and working with the practice nuances relating to cultural/country context will call on social workers to recognize and utilise skills of political engagement in their quest towards more engaged family focused work. This political approach is also recognized in the wider literature with the concern that this is an underdeveloped focus in the profession of social work (Shamai, 1997; Baum, 2007; Author, 2012). 
Agencies are expected to translate general policy guidelines into specific procedures, and front line staff are expected to translate specific procedures into interventions with clients, an approach aligned to what Ferguson previously referred to as 'negotiated casework' (2005:793). The UK's Think Family made direct reference to the importance of 'engagement' with reference to families described as 'hard to reach': "Practitioners should be given the confidence and skills to work assertively and creatively to engage families who are reluctant to accept support. Families with entrenched problems may be wary of services and it can be hard for them to motivate themselves and engage with support. Therefore, failing to meet appointments or declining help should not mean that the family is forgotten. Practitioners who are proactive and persistent have had considerable success in engaging some of the most excluded families" (Cabinet Office, Social ExclusionTask Force 2008, para. 3.16, quoted in Parton, 2009, 76). Training, and its related resources, can be a key element in assuring the development of necessary confidence and skills (Trevithick, 2012).

We suggest cultural considerations are linked with policy implementation in two ways. First, policy implementation is more likely to succeed when workers are in agreement with critical elements of the policy, otherwise they may engage in street-level practices that undermine the policy intent (Lipsky, 1980). Family-oriented cultures are likely to produce workers for whom family-engagement practices are a comfortable fit. This was noted by Benbenishty et al, 2015 as being influenced by the existence of rights based legislation in particular. In addition, Tew (2006) points out the importance of participatory employment cultures being more likely to encourage social workers to achieve engagement approaches in their work. Because "family" is valued to some 
extent in all cultures, "family engagement" may offer practice principles that the majority of workers firmly support. Issues of cultural competence are also relevant as workers and clients from different cultural backgrounds may lack a shared understanding of extent and nuances of family engagement practice.

Second, because family engagement resonates particularly well in traditional cultures, this may facilitate the adoption of these models. In countries with less developed systems of child protection, there is potential to build from the ground up with familyoriented norms. In New Zealand, the cultural principle of family participation in child welfare practice was subsequently written into formal policy (Worrall, 2001), emphasizing a bottom-up rather than top-down implementation approach. On the contrary, countries with a long history of systems of child protection (US and UK) continue to struggle to infuse more family-oriented practice into systems that were not originally designed with this value system. For this reason, Sweden and South Korea may have some advantage in efforts to implement practices related to family engagement. This observation is also consistent with path-dependency theories of policy implementation (Pierson, 2000). Once formal policy systems are in place, large scale redesign becomes substantially more difficult.

As we have noted, these policies and practices of family engagement occur within larger policy systems of social welfare and rights-orientation. In the case of the UK, it could be argued that this spirit of 'engagement' undergirding Think Family marks a departure away from its otherwise residualist approach to welfare. Parton (2010) suggests that such initiatives occurred against a New Labour government ideological commitment to tackling social exclusion, and within this, seeing the family as important 
in developing and nurturing the citizens of the future. The role of government in producing changes toward family engagement practice may be partly a factor of institutionalized political systems and partially linked with culture as well. Thus, although South Korea demonstrates cultural values toward family life, this does not necessarily translate into government supports for families; political perspectives might suggest that social services for families would be detrimental to cultural views regarding the preeminence of caretaking roles by family members (Shin \& Shaw, 2003). These political and cultural arguments about the role of government in family life are a chronic fundamental tension in the U.S. but are not typically controversial in Sweden.

The nature and methods of comparative inquiry typically require a small number of cases to compare and a limited number of variables to assess. Thus, our contribution is limited to the assessment of four countries on a few dimensions. One way to advance knowledge development is to include additional cases (i.e., countries) in a comparative analysis. At this time, additional advanced industrial democracies with professional social work would be of most use in comparative work. Movement beyond European comparisons is needed, however.

In regard to the dimensions of analysis we examined, how the profession of social work is organized and practiced may be a key element that involves further scrutiny. Some studies that have compared the profession of social work across countries have identified intriguing differences in the organization, status, and practice of the profession (e.g., Weiss-Gal and Welbourne, 2008; Spolander, Pullen-Sansfaçon, Brown, \& Engelbrecht, 2011). 


\section{Conclusion}

We began our paper suggesting the principles of family engagement resonate across the world in a variety of different contexts. While there are some differences in how this may be interpreted, there does seem to be widespread commitment to the ideals implicit in family engagement.

Achieving family focused intervention will necessarily require social workers to adopt political skills of engagement in their work with service users. This type of political approach will call for skills of reflexivity wherein the social worker can critically appraise the impact of wider macro factors in how they approach work with families. In challenging times, this may call for social workers to defend their approach to family engagement when facing criticism in the media, for example in the wake of tragedies as we have seen so often in the UK. Parton's observations about the 'watershed' impact of the 'Baby P' tragedy on the 'politics of child protection' underscores this point (2014: 69). Is it acceptable for social workers to unquestioningly accept the crisis driven orientation of their practice that flowed from such a high profile tragedy and indeed the type of 'aggressive authoritarianism' which now imbues child protection social work? (Parton, 2014:88). We know from research evidence already referred to in this paper, that family focus practice can lead to better outcomes for families and children. If social workers fail to question the macro factors driving and shaping their practice landscape, ultimately their practice is impoverished as a result. At other times, such politically based practice may require social workers to exert influence on policy makers to challenge taken for granted and historic assumptions about family life which have been 
engrained and cultivated through philosophical doctrine, such as the case we describe in S Korea.

As always, the more difficult challenge is implementation of ideals into practice. Our study has been limited by the selection of only four countries and we faced the perennial challenge of examining international comparisons when the preponderance of written evidence available for review comes from the US and UK. Nonetheless, given the increasing international context of practice, shared information across boundaries, and popularity of principles of family engagement, we offered this comparison to further understanding of similarities and differences in policy and practice. As policy and practice in this area continue to advance, additional attention to other areas of the world will increase knowledge of the parameters of family-focused intervention. 


\section{References}

Adoption and Safe Families Act (1997) P.L. 105-89.

Author (2007)

Author (2008)

Author (2009)

Author (2010)

Author (2012)

Bainham, A. (2005). Children: The modern law (3rd ed.). Bristol, UK: Family Law.

Bell, M. (2002) 'Promoting children's rights through the use of relationship', Child and Family Social Work, 7, pp. 1-11.

Baum, N. (2007) 'Social Work Practice in Conflict-ridden Areas: Cultural Sensitivity is Not Enough', British Journal of Social Work 37: 873-91.

Benbenishtya, R.,Davidson-Arad, B., Mónica Lópezc, M., Devaney, J., Spratt, T., Koopmans, C., Knorth, E.J., Witteman, C.L.M., Del Valleg, J.F and Hayes, D. (2015) Decision making in child protection: An international comparative study on maltreatment substantiation, risk assessment and interventions recommendations, and the role of professionals' child welfare attitudes Child Abuse \& Neglect $4963-75$

Buckley, H., Carr, N. and Whelan, S. (2011) Like walking on eggshells: Service user views and expectations of the child protection system', Child \& Family Social Work. 16(1): 101-10.

Buford, G. (2000). Advancing innovations: Family group decision making as community-centered child and family work. Protecting Children, 16, 4-20. 
Cabinet Office, Social Exclusion Task Force. (2008). Think Family: Improving the Life Chances of Families at Risk. Cabinet Office, London.

Cameron, G., \& Freymond, N. (2006) Understanding international comparisons of child protection, family service, and community systems of child and family welfare. In N. Fraymond \& G. Cameron (Eds), Towards positive systems of child and family welfare (pp. 3-26). Toronto: Toronto University Press Inc.

Carter, J. (2006). What's right for children? Emory International Law Review, 20, 1-7.

Center for the Study of Social Policy (CSSP). (2012). For the welfare of children: Lessons learned from class action litigation. Washington DC: CSSP.

Cocozza, M., \& Hort, S.E.O. (2011). The dark side of the universal welfare state: Child abuse and protection in Sweden. In N. Gilbert, N. Parton, \& M. Skivenes (Eds). (2011). Child protection systems: International trends and orientations (pp. 89-111). New York, Oxford University Press.

Cohen, C. P. (1992). The relevance of theories of natural law and legal positivism. In M.

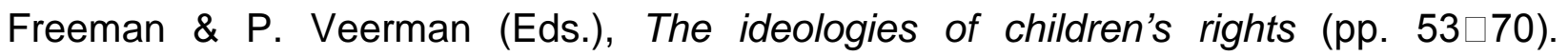
Dordrecht: Martinus Nijhoff Publishers.

Collier, D. (1993). The Comparative method. In, A.W. Finifter (Ed.). Political Science: The State of the Discipline II (pp. 105-119). Washington, D.C.: American Political Science Association.

Colton, M., \& Williams, M. (Eds). (2006). Global perspectives on family foster care. Dorset, UK: Russell House Publishing.

Cree, V.E. \& Davis, A. (2007) Social Work - Voices from the Inside. London and New York: Routledge. 
Damman, J (2014) "Birth parent involvement: Developing indicators to establish meaningful involvement" Conference paper. Kansas University. 14 November, 2014.

Daly, M (2011) Welfare. Cambridge: Polity Press.

Darlington, Y., Healy, K., \& Feeney, J.A. (2010). Challenges in implementing participatory practice in child protection: A contingency approach. Children and Youth Services Review, 32, 1020-1027.

Davey, J., \& Bigmore, J. (2009) Introducing child care social work: Contemporary policy and practice. Essex, UK: Learning Matters.

Department for Education and Skills. (2004). Every Child Matters: Change for Children in Social Care. London, UK: Her Majesty's Stationery Office (HMSO).

Desai, M. (2009). A comparative study of policy approach for child protection in Goa and Singapore. Children and Youth Services Review, 31, 32-39.

Detrick, S. (1999). A commentary on the United Nations Convention on the Rights of the Child. The Hague: Martinus Nijhoff Publishers.

Doe, S.S. (2000). Cultural factors in child maltreatment and domestic violence in Korea. Children and Youth Services Review, 22, 3/4, 231-236.

Ferguson, $\mathrm{H}$ (2005) 'Working with Violence, the Emotions and the Psycho-social Dynamics of Child Protection: Reflections on the Victoria Climbié Case'. Social Work Education: The International Journal, Vol 24(7):781-795.

Fostering Connections to Success and Increasing Adoptions Act (2008) P.L. 110-351.

Freeman, M., \& Veerman, P. (Eds.). (1992). The ideologies of children's rights. London: Martinus Nijhoff. 
Gerring, C. E., Kemp, S.P., and Marcenko, M.O. (2008). The Connections Project: A relational approach to engaging birth parents in visitation. Child Welfare, 87, 6, 5-30.

Gilbert, N. (1997) Combating child abuse. International perspectives and trends. Oxford: Oxford University Press.

Gilbert, N., Parton, N., \& Skivenes, M. (Eds.) (2011).Child protection systems: International trends and orientations. New York, Oxford University Press.

Glendon, M.A. (1992). Rights in twentieth-century constitutions. University of Chicago Law Review, 59, 519-538.

Gunn, T. J. (2006). The religious right and the opposition to U.S. ratification of the Convention on the Rights of the Child. Emory International Law Review, 20, 112-128.

Hong, J.S., Stokes, C., Byoun, S.J., Furuto, S.B.C.L., and Kim, Y.S. (2011). Integrating cultural competency in South Korean social work education. International Social Work, 56(2), 180-192.

Hill, M., \& Hupe, P. (2002). Implementing public policy. London: Sage.

Höjer, S., \& Forkby, T. (2011). Care for sale: The influence of new public management in child protection in Sweden. British Journal of Social Work, 41, 93-110.

Jowitt, M., \& O'Loughlin, S. (2005). Social work with children and families. Exeter: Learning Matters Ltd.

Ju, S.Y., \& Lee, Y.H. (2010). Experiences of family maltreatment by Korean children in Korean National Protective Services. Child Abuse and Neglect, 34, 18-27.

Kagan, S.L., \& Weissbourd, B. (Eds.). (1994). Putting families first: America's family support movement and the challenge of change. San Francisco: Jossey-Bass Publishers. 
Katz, I., \& Hetherington, R. (2006) Co-operating and communicating: A European perspective on integrating services for children. Child Abuse Review, 15, 6, 429-439.

Khoo, E, Hyvönen, U., \& Nygren, L (2002). Child welfare or child protection: Uncovering Swedish and Canadian orientations to social intervention in child maltreatment. Qualitative Social Work, 1, 4, 451-471.

Kim, U., Park, Y.S., Kwon, Y.E., \& Koo, J. (2005). Values of children, parent-child relationship, and social change in Korea: Indigenous, cultural, and psychological analysis. Applied Psychology: An International Review, 54, 3, 338-354.

Kirton, D. (2009). Child social work policy and practice. London: SAGE Publications. Krumer-Nevo, M. (2003). From 'a coalition of despair' to 'a covenant of help" in social work with families in distress. European Journal of Social Work, 6, 3, 273-282. Laming (2003) The Victoria Climbié Inquiry Report. Sixth Report of Session 2002-03. London: The Stationery Office.

Lee, B.J. (2007). Adoption in Korea: Current status and future prospects. International Journal of Social Welfare, 16, 75-83.

Lee, H.E. (2011). Fifty years of the Child Welfare Act [in Korean]. Hankook-ilbo (1/17/2011). Available online at: www.hankooki.com (accessed January 14, 2011). Lipsky, M (1980). Street-level bureaucracy. New York: Russell Sage Foundation. Lundy, L (2007) Voice is not enough: Conceptualising Article 12 of the United Nations Convention on the Rights of the Child. British Educational Research Journal. 33(6), 6, p. $927-942$ 
Manful, E \& McCrystal, P (2010) Conceptualisation of Children's Rights: What Do Child Care Professionals in Northern Ireland Say? Child Care in Practice, 16:1, 83-97, DOI: $10.1080 / 13575270903381744$

Mason, M. A. (2005). The U.S. and the international children's rights crusade: Leader or laggard? Journal of Social History, 38, 955-963.

McCroskey, J. \& Meezan, W. 1998. Family-centered services: Approaches and effectiveness. The Future of Children, 8, 1, 54-71.

Mildred, J., \& Plummer, C.A. (2009). Responding to child sexual abuse in the United States and Kenya: Child protection and children's rights. Children and Youth Services Review, 31, 601-608.

Mischen, P.A. (2008). The impact of Child and Family Service Reviews on knowledge management. Child Welfare, 87, 125-143.

Mitchell, L., Thomas, M.L., and Parker, B. (2014). The children and family services review. In G.P. Mallon and P.M. Hess (Eds.) Child welfare for the 21st century: A handbook of practices, policies, and programs. (2nd edition, pp. 567-582). New York: Columbia University Press.

Morris, K., Brandon, M., and Tudor, P. (2015). Rights, responsibilities and pragmatic practice: Family participation in case reviews. Child Abuse Review, 24, 3, 198 - 209.

Munro, E. (2011) The Munro Review of Child Protection: Final Report: A Child Centred System. London, UK: The Stationery Office Limited.

NHRC (National Human Rights Commission). (2006). Recommendation proposal on National Action Plans for the Promotion and Protection of Human Rights (NAP). 
Norström, C., \& Thunved, A. (1996) Nya Sociallagarna - med kommentarer, lagaroch författningar som de lyder den 1 juli 1996 [The New Social Laws - with Commentary, Laws and Statutes effective 1 July 1996]. Stockholm: Norstedts Juridik.

Olsson Hort, S.E (1997). Toward a deresidualization of Swedish child welfare policy and practice. In N. Gilbert (Ed.) Combatting child abuse: International perspectives and trends (pp. 105-125). Oxford: Oxford University Press.

Parton, N. (2009). From Seebohm to Think Family: reflections on 40 years of policy change of statutory children's social work in England. Child and Family Social Work, 14, 1, 68-78.

Payne, M. (2006). What is professional social work? Bristol: The Policy Press.

Pierson, P. (2000). Increasing returns, path dependence, and the study of politics. American Political Science Review, 94, 2, 251-267.

Pinkerton, J. (2008). States of leaving care: Towards international exchange as a global resource. In, M. Stein \& E. R. Munro (Eds.), Young people's transitions from care to adulthood: International research and practice (pp. 241-257). London: Jessica Kingsley Publishers.

RCW (Representing Children Worldwide). (2005). How children's voice are heard in child protective proceedings. Available online at: www.law.yale.edu/rcw/jurisdictions/ase/repofkorea/frontpagel.htm (accessed January 13, 2011).

Rauktis, M.E., McCarthy, S., Krackhardt, D., \& Cahalane, H. (2010), Innovation in child welfare: The adoption and implementation of Family Group Decision Making in Pennsylvania. Children and Youth Services Review, 32, 732-739. 
Roose, R., \& De Bie, M. (2008). Children's rights: A challenge for social work. International Social Work, 51, 1, 37 - 46.

Roose, R., Roets, G., Van Houte, S., Vandenhole, W., Reynaert, D. (2013). From parental engagement to the engagement of social work services: Discussing reductionist and democratic forms of partnership with families. Child and Family Social Work, 18, 4, 449-457.

Saleeby, D. (Ed.) (2006) The Strengths Perspective in Social Work Practice, Fourth Edition. Boston: Allyn and Bacon/Longman

Scherrer, J.L. (2012). The United Nations Convention on the Rights of the Child as policy and strategy for social work action in child welfare in the United States. Social Work, 57, 1, 11-22.

Shamai, M. (1999) 'Experiencing and Coping with Stress of Political Uncertainty:

Gender Differences among Mental Health Professionals', Families in Society 1: $41-50$.

Shin, C., \& Shaw, I. (2003). Social policy in South Korea: Cultural and structural factors in the emergence of welfare. Social Policy and Administration, 37, 4, 328-341.

Smith, R. (2008) Social Work and Power. Basingstoke: Palgrave Macmillan.

Smith, M., Gallagher, M., Wosu, H., Stewart, J., Cree, V.E., Hunter, S., Evans, S., Montgomery, C., Holiday, S., Wilkinson, H. (2011) 'Engaging with Involuntary Service Users in Social Work: Findings from a Knowledge Exchange Project' British Journal of Social Work. DOI: 10.1093/bjsw/bcr162. pp: 1-18. 
Social Security Administration. (2016). Title IV grants to states for aid and services to needy families with children and child welfare services. Retrieved from ssa.gov/OP_Home/ssact/title04/0400.htm.

Spolander, G., Pullen-Sansfaçon, A., Brown, M., \& Engelbrecht, L. (2011). Social work education in Canada, England and South Africa: A critical examination of curriculums and programmes. International Social Work, 54,817-832.

Spratt, T., \& Callan, J. (2004). Parents' views on social work interventions in child welfare cases. British Journal of Social Work, 34, 199-244.

Sundell, K., Vinnerljung, B., \& Ryburn, M. (2001). Social workers' attitudes towards family group conferences in Sweden and the UK. Child and Family Social Work, 6, 327336.

Tew, J (2006) 'Understanding Power and Powerlessness: Towards a Framework for Emancipatory Practice in Social Work' Journal of Social Work. Vol 6(1): 33-51.

Trevithick, P. (2012) Social Work Skills and Knowledge: A Practice Handbook. 3rd ed. Maidenhead: Open University Press.

Trotter, C. (2006) Working with Involuntary Clients - A Guide to Practice. London: Sage Publications.

Waites, C., Macgowan, M., Pennell, J., Carlton-LaNey, I., \& Weil, M. (2004). Increasing the cultural responsiveness of family group conferencing. Social Work, 29, 291-301.

Weissbrodt, D. (2006). Prospects for ratification of the Convention on the Rights of the Child. Emory International Law Review, 20, 210-216. 
Weiss-Gal, I., \& Welbourne, P. (2008). The professionalization of social work: A crossnational exploration. International Journal of Social Welfare, 17, 281-290.

Winter, K (2011) The UNCRC and social workers' relationships with young children, Child Abuse Review. 20, 6, p. 395-406 DOI: 10.1002/car.1203

Winter, K (2014) Understanding and Supporting Young Children's Transitions into State Care: Schlossberg's Transition Framework and Child-Centred Practice. British Journal of Social Work. 44, 2, p. 401-417

Wolf, R., Biesel, K., \& Heinitz, S. (2011). Child protection in an age of uncertainty: Germany's response. In N. Gilbert, N. Parton, \& M. Skivenes (Eds.), Child protection systems: International trends and orientations (pp. 183-203). Oxford: Oxford University Press.

Woolfson, R.C, Heffernan, E, Paul, M., \& Brown, M. (2010) Young people's views of the child protection system in Scotland. British Journal of Social Work, 40, 2069-2085.

Worrall, J. (2001). Kinship care of the abused child: The New Zealand experience. Child Welfare, 80, 497-511.

Yang, S.N., \& Shin, C.S. (2008). Parental attitudes towards education: What matters for children's well-being? Children and Youth Services Review, 20, 1328-1335.

Yoon, H.M. (1997). Concepts of child abuse and neglect. A survey of the general public and professionals about their perceptions of social interventions concerning child maltreatment. Korean Journal of Social Welfare [in Korean], 31, 393-422.

Young, S., McKenzie, M., Schjelderup, L.,More, C and Walker, S (2014) What Can We Do to Bring the Sparkle Back into this Child's Eyes? Child Rights/ Community 
Development Principles: Key Elements for a Strengths-based Child Protection Practice, Child Care in Practice, 20:1, 135-152, DOI: 10.1080/13575279.2013.847052 